\title{
Micro-Sandblasting and Sulfonation of PEEK Dental Implants
}

\author{
Merlo Diego $^{1 *}$, Belloni Federico ${ }^{2}$, De Landaburu Federico ${ }^{3}$, Dalessandro José ${ }^{4}$, Escudero Ezequiel ${ }^{5}$, \\ Butler Teresa ${ }^{6}$, Lazo Sergio ${ }^{7}$, Abal Adrian ${ }^{8}$. \\ 1. Odontólogo, Facultad de Odontología Universidad Nacional La Plata. Argentina \\ 2. Odontólogo, Facultad de Odontología Universidad Nacional La Plata. Argentina \\ 3. Odontólogo, Facultad de Odontología Universidad Nacional La Plata. Argentina \\ 4. Odontólogo, Facultad de Odontología Universidad Nacional La Plata. Argentina \\ 5. Dr. Odontólogo, Facultad de Odontología Universidad Nacional La Plata. Argentina \\ 6. Dra. Odontólogo, Facultad de Odontología Universidad Nacional La Plata. Argentina \\ 7. Dr. Odontólogo, Facultad de Odontología Universidad Nacional La Plata. Argentina \\ 8. Dr. Odontólogo, Facultad de Odontología Universidad Nacional La Plata. Argentina \\ * dieguitomerlo@hotmail.com
}

PEEK, a thermoplastic polymer that has mechanical properties comparable to those of bone. This new material shows excellent mechanical properties, in particular a modulus of elasticity comparable to that of cortical bone [1]. In the area of medical traumatology it is recognized as a bioinert material and in clinical studies it was observed that superficial modification with bioactive reagents increases the fixation of PEEK with bone [2].

It was proposed in the work to perform two procedures for PEEK implants at the superficial level, Microsanding and Sulfonation. The initial characterization of the peek implants was carried out with an Aluminum Oxide Micro-sanding of different granulometries and taking into account the distance and exposure time, a table was prepared to follow a surface micro-sandblasting protocol.

The PEEK surface showed to be a very treatable material and with effective results with sandblasting with Aluminum Oxide. This methodology of mechanical treatment was very satisfactory but the sense of the investigation led to postulate another alternative method of chemical treatment called Sulfonation.

By establishing an immersion protocol, the molecular structure of PEEK was changed through the use of sulfuric acid and inactivated with carbonated potassium [3]. Through the Physical Metallurgy Research Laboratory (LIMF) it was observed by Scanning Electron Microscopy using a SEM FEI Quanta200 microscope.

The results show very satisfactory measures due to the notable change in the formation of pores with the Micro-sandblasting and in terms of immersion mechanisms suggest that PEEK with treated surface and without observable toxicity is a material that has great clinical potential. [4]. Under an optical microscope, mature osteoblasts are large, cuboid-shaped cells, 20-30 um; therefore, cell proliferation in this medium proposes better cell induction and implant bone integration. These observations taken to the clinic and at the place of insertion of said element allows us to think about the similarity with the spongy of the trabeculae and that this led to natural biology determines us an ideal substrate and scaffolding for cell proliferation. Studies on PEEK show that the untreated surface shows no signs in any laboratory work of cell induction.

Do these phenomena produced by sulfonation allow better cell replication? Due to this treatment, does PEEK change its inert surface structure to an osteoinductive surface? 
Although the initial samples have all the features of this, in subsequent work carried out in culture media we can develop the result better, as well as compression and fatigue measurement tests to corroborate if these changes entail a weakness in the subject matter. study. Subsequent in vitro tests are necessary to evaluate the bioactive mechanism of the surface treatment process described in these studies.

Referencias:

[1] "Schwitalla,et al, Mueller et al, PEEK dental implants: A Review of the Literature. Journal of Oral Implantology "39(6) (2011)

[2] " FeiChen et al., Fracture characteristics of PEEK at various stress triaxialities, Journal of the

Mechanical Behavior of Biomedical Materials", Volume 64, (2016) Pages 173-186

[3] "Qiuyan et al, Guo He, Gelatin et al -enhanced porous titanium loaded with gentamicin sulphate and in vitro release behavior, Materials and Design 99" (2016).

[4] "Rahmitasari et al., PEEK with Reinforced Materials and Modifications for Dental Implant Applications, Dentistry journal" (2017).
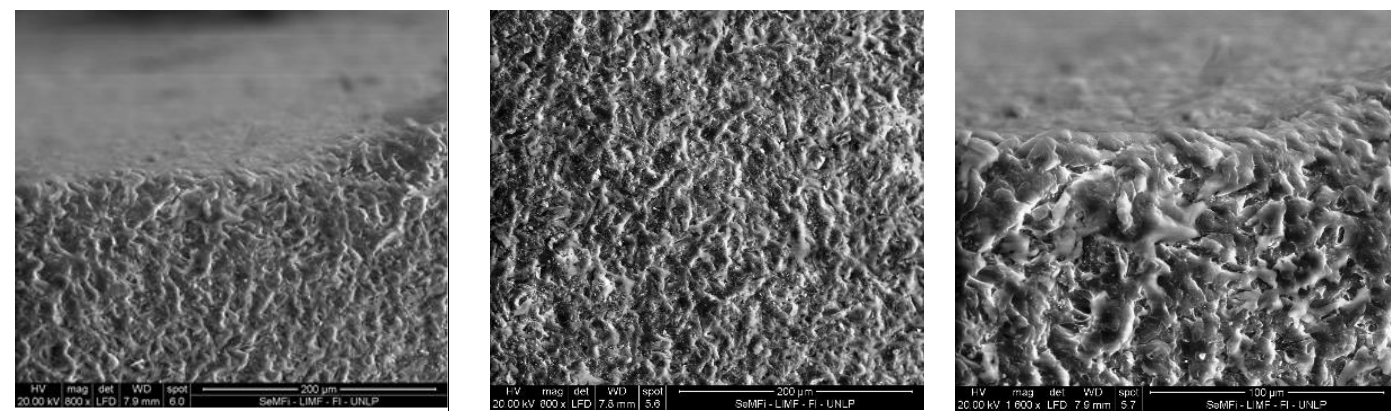

Figure 1: Quanta 200 Scanning Electron Microscope Micrograph. Images at different magnifications of a PEEK-Optima material specimen. Sample of the surface of the PEEK who proved to be a very treatable material and with effective results with sandblasting with Aluminum Oxide achieving a rough substrate very different from the source material.
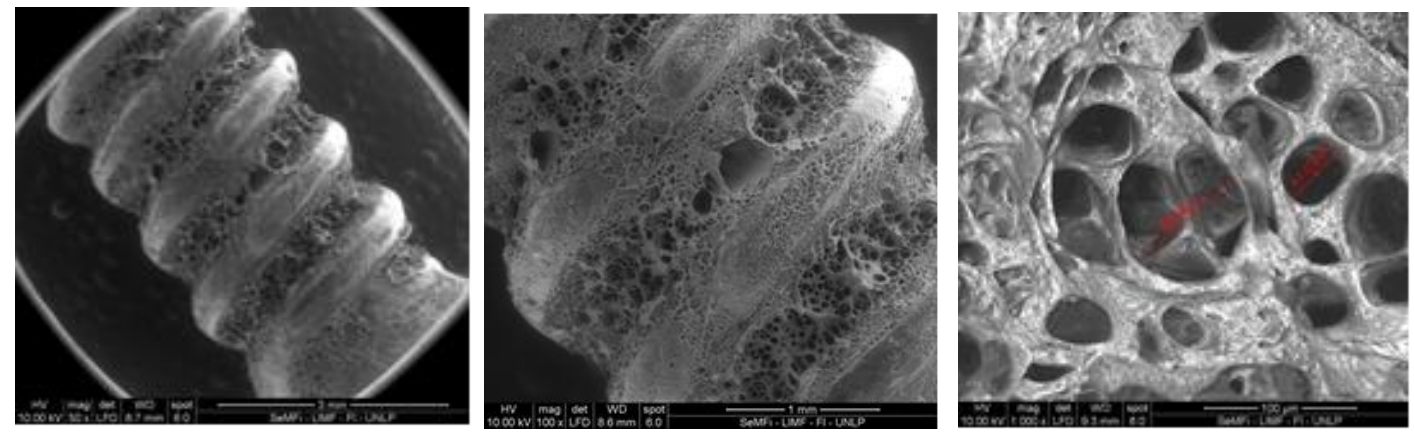

Figure 2: Scanning electron microscopy micrograph Quanta 200. Images of a PEEK dental implant (polyether ether ketone), manufactured at the Faculty of Dentistry of La Plata U.N.L.P. the immersion in sulfuric acid with its subsequent chemical neutralization managed to create a surface that is confused to that of a human spongy bone, with the purpose of improving bone-implant integration. 